\title{
Effect of Withdrawal of Dietary Sodium in Hypertensive and Normotensive Rats
}

\author{
Akio Ebihara, M. D.,* B. L. Martz, M.D.,* \\ and Arthur Grollman, M.D.
}

\section{SUMMARY}

The effect of withdrawing dietary sodium was determined in 10 rats with marked hypertension induced by ligation of a branch of the renal artery and contralateral nephrectomy and in 10 normal control animals. No significant change occurred in the systolic blood pressure of either group of animals during 5 days of sodium withdrawal. Throughout the period of observation, the urinary output was greater in the hypertensive than in the normotensive group. Reduction of urinary output and water intake was observed in both groups during sodium depletion. The reduction in the urinary excretion of sodium was greater in the hypertensives than in the normal animals for several days after sodium was withdrawn. Hypertensive rats, accordingly, retain sodium more efficiently than do normotensives after sodium withdrawal.

\section{Additional Indexing Words :}

Hypertension Sodium restriction in rats Ligation of branch of renal artery and contralateral nephrectomy in rats Urinary output in hypertension Urinary excretion of sodium in hypertension Aldosterone stimulating effect of sodium depletion.

$\mathrm{P}$ ERERA and Blood"1 first noted a difference in the responses to salt restriction of hypertensive and normotensive human subjects. They observed that the significant weight loss and increased urinary output which followed sodium restriction in normotensive subjects were not evident in hypertensive patients. Sodium and chloride clearances were minimal in 2 normotensives but were reduced appreciably in 2 hypertensive subjects. Renwick et al., ${ }^{2)}$ on the other hand, were unable to confirm this difference in the response to sodium restriction between hypertensive and normotensive patients. Because of the importance of the problem for a better understanding of the nature of hyper-

From the Lilly Laboratory for Clinical Research, Marion County General Hospital, Indianapolis, Indiana, 46207.

* Department of Experimental Medicine, University of Texas Southwestern Medical School, Dallas, Texas.

Dr. Ebihara's present address: The Second Department of Internal Medicine, Faculty of Medicine, University of Tokyo, Tokyo.

Received for publication November 22, 1969. 
tensive disease, the present study was undertaken using rats with marked hypertension and normotensive controls under rigid experimental conditions not attainable with human subjects.

\section{METHODS}

Adult male rats of the Wistar strain, 220-270 Gm. in weight, were used. The hypertensive group consisted of 10 rats with chronic hypertension (systolic blood pressure, 160 to $210 \mathrm{~mm}$. $\mathrm{Hg}$ ) induced by ligation of a branch of one renal artery and contralateral nephrectomy as described by Loomis. ${ }^{3)}$ Only rats with a sustained systolic blood pressure over $160 \mathrm{~mm}$. $\mathrm{Hg}$ for more than 4 weeks were used.

As controls, 10 intact normotensive rats (systolic blood pressure, 100 to $120 \mathrm{~mm}$. $\mathrm{Hg}$ ) were selected which were comparable to the hypertensive group in body weight and age. All animals were kept in individual metabolic cages in order to collect clean urine without contamination of feces (Fig. 1). The food used in these studies was a commercial sodium deficient diet (Nutritional Biochemicals Corp, Cleveland, Ohio) containing, according to the anlysis in this laboratory, $0.00 \%$ of sodium and $0.78 \%$ of potassium. After a 5-day preliminary control period on the diet into which $1 \%$ in weight of sodium chloride was thoroughly mixed (first control period), the same diet without the addition of salt was used for 5 days (experimental period) followed by another 5 days on the diet plus salt (second control period). As shown in Fig. 2, $7 \mathrm{Gm}$. of the dry food dissolved in $4 \mathrm{ml}$. of $0.3 \%$ aqueous methyl cellulose solution was administered by gavage to each rat through a plastic tube attached

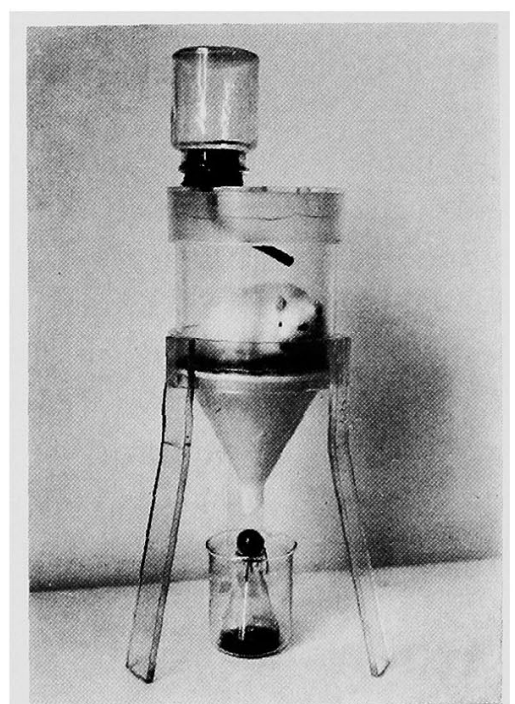

Fig. 1. All animals were kept in metabolism cages made in this laboratory throughout the whole experimental period to collect clean urine without contamination of feces. Urine came down into the Erlenmeyer flask through the ditches made around the glass bulb which also could prevent evaporation of urine. 


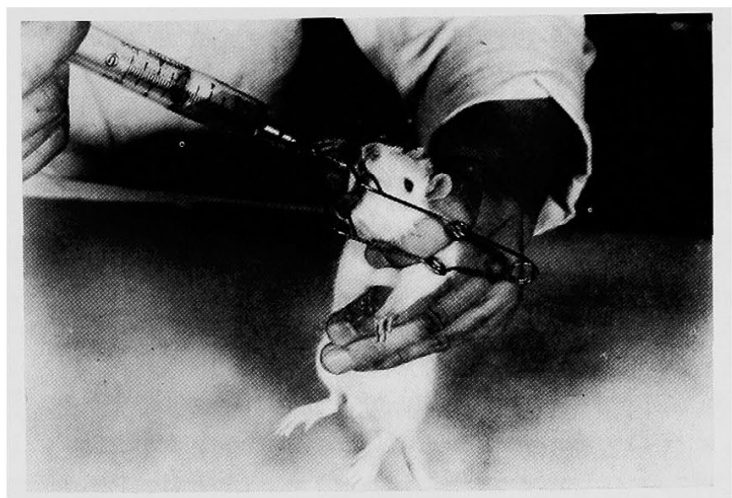

Fig. 2. A constant amount of food dissolved into methylcellulose aquous solution was put into the stomach by a tube attached to a syringe twice daily.

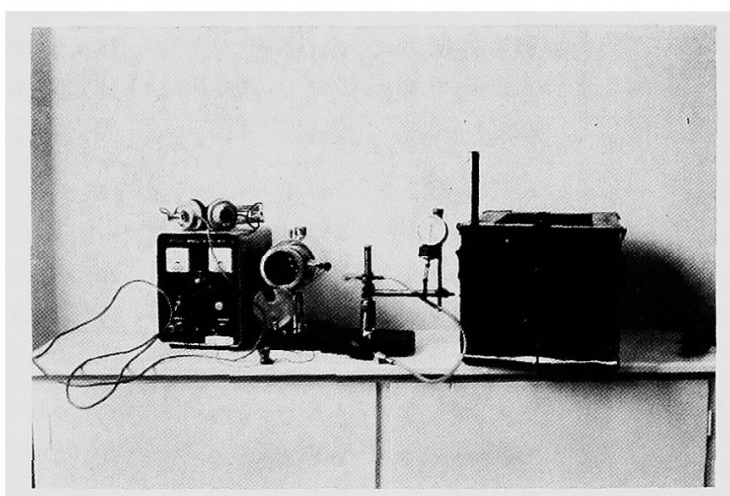

Fig. 3. The systolic blood pressure of the rat was determined by the tail microphonic method, using the apparatus shown in this figure.

to a syringe, twice daily. Urine was collected for 24-hr periods daily, its volume measured, and part frozen for the later determination of its osmotic pressure and electrolyte content. All animals had access to distilled water in spillproof bottles ad libitum.

Body weights and water intake were recorded daily. Osmotic pressure of urine was measured with an Advance Instruments freezing-point osmometer. Urinary sodium and potassium were determined by an autoanalyzer flame photometer, chloride content by the Volhard-Harvey method.4) Systolic blood pressures were determined by the tail microphonic method, ${ }^{5)}$ using the apparatus shown in Fig. 3, daily without anesthesia after warming the rat for $10 \mathrm{~min}$. at $38^{\circ} \mathrm{C}$.

The animals were kept for 3 days preceding the experiment in individual metabolism cages in order to accustom them to the experimental conditions. During this period they were fed the test diet, to which $1 \%$ sodium chloride had been added, by stomach tube, and given distilled water as drinking fluid as in the experimental period. The data were analyzed by Students" " $t$ " test for 95\% confidence limit. 


\section{Results}

\section{Body weight and blood pressure (Table I)}

Body weights in both hypertensive and normotensive groups showed no significant changes throughout the experiment. There was also no significant change in the systolic blood pressure during dietary sodium restriction.

Table I. Changes in Body Weight and Systolic Blood Pressure of Hypertensive and Normotensive Rats

\begin{tabular}{l|c|cc|cc}
\hline \multirow{2}{*}{ Period } & Day & Hypertensive & Normotensive & \multicolumn{2}{|c}{ Blood Pressure, mm. Hg } \\
& & Hypertensive & Normotensive \\
\hline & 1 & $250.1 \pm 10.4$ & $243.9 \pm 4.8$ & $178.3 \pm 3.2$ & $115.1 \pm 2.6$ \\
Control 1 & 2 & $257.4 \pm 6.5$ & $242.9 \pm 5.4$ & $182.0 \pm 6.3$ & $111.2 \pm 1.5$ \\
(sodium added) & 3 & $255.4 \pm 6.9$ & $241.8 \pm 5.1$ & $182.0 \pm 6.1$ & $115.2 \pm 4.3$ \\
& 4 & $256.9 \pm 6.8$ & $241.9 \pm 5.1$ & $177.7 \pm 6.3$ & $113.2 \pm 4.0$ \\
& 5 & $255.1 \pm 6.7$ & $244.6 \pm 4.4$ & $181.0 \pm 7.0$ & $113.6 \pm 3.0$ \\
\hline & 6 & $257.9 \pm 5.7$ & $244.8 \pm 4.3$ & $181.0 \pm 5.7$ & $115.6 \pm 2.0$ \\
Experimental & 7 & $256.1 \pm 5.5$ & $245.1 \pm 4.8$ & $179.7 \pm 5.5$ & $112.0 \pm 3.7$ \\
(no sodium) & 8 & $256.3 \pm 5.4$ & $245.0 \pm 4.3$ & $181.3 \pm 5.1$ & $114.4 \pm 2.6$ \\
& 9 & $258.3 \pm 4.1$ & $245.0 \pm 4.5$ & $179.7 \pm 4.4$ & $115.5 \pm 3.1$ \\
& 10 & $258.6 \pm 5.4$ & $245.3 \pm 4.8$ & $182.0 \pm 5.1$ & $115.2 \pm 3.0$ \\
\hline & 11 & $259.3 \pm 5.3$ & $246.0 \pm 4.4$ & $177.3 \pm 3.8$ & $113.2 \pm 2.3$ \\
& 12 & $267.6 \pm 5.1$ & $248.1 \pm 5.2$ & $181.0 \pm 3.4$ & $114.4 \pm 3.0$ \\
Control 2 & 13 & $264.4 \pm 5.2$ & $246.1 \pm 4.6$ & $185.0 \pm 7.4$ & $115.6 \pm 3.4$ \\
(sodium restored) & 14 & $264.6 \pm 5.4$ & $245.9 \pm 4.8$ & $182.7 \pm 7.3$ & $112.4 \pm 6.0$ \\
& 15 & $264.0 \pm 5.2$ & $247.5 \pm 5.1$ & $190.3 \pm 6.7$ & $112.4 \pm 2.7$ \\
& & & & &
\end{tabular}

Values are expressed as means $\pm \mathrm{SE}$.

\section{Urinary output, urinary osmolarity and water intake (Table II).}

Throughout the entire experimental period, the hypertensive rats excreted more urine than the normotensive controls. After withdrawal of sodium from the diet, the urine volume decreased in both groups. This decrease in urine volume from the average of the first control period was statistically significant for the first 4 days after sodium withdrawal in both groups. No difference was found in the rate of change of urine volume between the 2 groups. The urinary output returned to the control level after sodium was restored to the diet in both groups. The osmotic pressure of the urine was inversely proportional to the urine volume and lower in the hypertensive rats than in the normotensives throughout the period of observation. No signifcant change was found between the osmotic pressure of urine in the first and 
Table II. Effects of Sodium Restriction on the Urinary Output, Urinary Osmolarity and Water Intake of Hypertensive and Normotensive Rats

\begin{tabular}{|c|c|c|c|c|c|c|c|}
\hline Period & Day & $\begin{array}{l}\text { Urinary } \\
\text { ml./24 } \\
\text { Hyperten- } \\
\text { sive }\end{array}$ & $\begin{array}{l}\text { Output } \\
\text { hours } \\
\text { Normoten- } \\
\quad \text { sive }\end{array}$ & $\begin{array}{c}\text { Urinary Oss } \\
\text { Os } \\
\text { Hyperten- } \\
\text { sive }\end{array}$ & $\begin{array}{l}\text { notic Pressure } \\
\text { n/L. } \\
\text { Normoten- } \\
\text { sive }\end{array}$ & $\begin{array}{l}\text { Water } \\
\text { ml. } / 24 \\
\text { Hyperten- } \\
\text { sive }\end{array}$ & $\begin{array}{l}\text { Intake } \\
\text { hours } \\
\text { Normoten- } \\
\text { sive }\end{array}$ \\
\hline \multirow{5}{*}{ 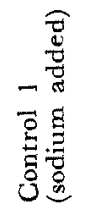 } & 1 & $15.3 \pm 1.5$ & $7.6 \pm 0.7$ & $1.00 \pm 0.06$ & $1.91 \pm 0.13$ & $19.1 \pm 1.3$ & $13.6 \pm 1.1$ \\
\hline & 2 & $16.2 \pm 1.2$ & $7.9 \pm 0.9$ & $0.96 \pm 0.07$ & $1.98 \pm 0.13$ & $19.7 \pm 1.1$ & $11.4 \pm 1.3$ \\
\hline & 3 & $16.1 \pm 1.3$ & $7.1 \pm 0.7$ & $1.04 \pm 0.08$ & $1.92 \pm 0.15$ & $20.4 \pm 2.0$ & $13.5 \pm 0.1$ \\
\hline & 4 & $15.0 \pm 1.2$ & $7.4 \pm 0.7$ & $1.15 \pm 0.10$ & $2.26 \pm 0.14$ & $17.6 \pm 1.6$ & $13.6 \pm 0.4$ \\
\hline & 5 & $14.4 \pm 1.2$ & $7.3 \pm 0.6$ & $1.17 \pm 0.09$ & $1.96 \pm 0.10$ & $18.4 \pm 0.6$ & $12.0 \pm 0.3$ \\
\hline \multirow{5}{*}{ 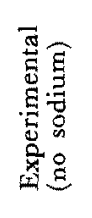 } & 6 & $12.1 \pm 1.5 *$ & $4.5 \pm 0.8 * * *$ & $1.05 \pm 0.17$ & $2.13 \pm 0.10$ & $15.4 \pm 1.2^{* * *}$ & $9.1 \pm 0.6^{* * *}$ \\
\hline & 7 & $10.0 \pm 1.0^{* * *}$ & $5.0 \pm 0.9^{* * * *}$ & $1.18 \pm 0.12$ & $2.30 \pm 0.23$ & $15.0 \pm 1.2^{* *}$ & $10.1 \pm 0.6$ \\
\hline & 8 & $11.1 \pm 1.6^{* * *}$ & * $5.1 \pm 0.7 * * *$ & $1.24 \pm 0.17$ & $2.06 \pm 0.20$ & $16.0 \pm 1.2$ & $10.3 \pm 0.9$ \\
\hline & 9 & $12.2 \pm 1.8^{*}$ & $5.6 \pm 0.8^{*}$ & $0.88 \pm 0.13$ & $2.44 \pm 0.31$ & $15.9 \pm 1.3$ & $11.3 \pm 1.0$ \\
\hline & 10 & $14.8 \pm 2.2$ & $6.8 \pm 0.8$ & $0.94 \pm 0.11$ & $2.02 \pm 0.23$ & $17.4 \pm 2.3$ & $11.0 \pm 1.2^{*}$ \\
\hline \multirow{5}{*}{ 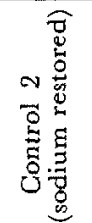 } & 11 & $13.8 \pm 0.9$ & $7.0 \pm 1.1$ & $1.06 \pm 0.06$ & $2.21 \pm 0.36$ & $20.6 \pm 1.2$ & $12.9 \pm 0.6$ \\
\hline & 12 & $18.4 \pm 2.1$ & $8.3 \pm 1.4$ & $0.87 \pm 0.09$ & $2.27 \pm 0.22$ & $19.0 \pm 1.2$ & $10.1 \pm 1.3$ \\
\hline & 13 & $19.6 \pm 2.9$ & $7.4 \pm 0.8$ & $0.88 \pm 0.07$ & $2.25 \pm 0.21$ & $20.9 \pm 2.5$ & $12.5 \pm 2.4$ \\
\hline & 14 & $19.5 \pm 2.8$ & $7.3 \pm 0.8$ & $0.89 \pm 0.10$ & $2.29 \pm 0.14$ & $20.3 \pm 3.4$ & $13.4 \pm 0.7$ \\
\hline & 15 & $22.1 \pm 4.5$ & $7.0 \pm 0.7$ & $0.87 \pm 0.16$ & $2.33 \pm 0.27$ & $20.7 \pm 4.3$ & $10.9 \pm 1.0$ \\
\hline
\end{tabular}

Values are means $\pm \mathrm{SE}$.

* $\mathbf{P}$ value of difference from the mean in control period: $0.05 \gg 0.02$

** $\mathrm{P}$ value of difference from the mean in control period: $0.02 \gg 0.01$

*** $\mathrm{P}$ value of difference from the mean in control deriod: $0.01>$

second control periods. A reduction of water intake occurred in both groups during the period of sodium withdrawal from the diet. Restoration of dietary sodium was followed by a return of the water intake to its prior control level.

\section{Urinary excretion of electrolytes (Table III)}

There was no significant difference in the urinary excretion of electrolytes of the 2 groups during the 2 control periods. Urinary excretion of sodium decreased markedly immediately after sodium was withdrawn from the diet in both groups. During this period, the urinary excretion of sodium was significantly less in the hypertensive than in the normotensive rats, despite the fact that rats in both groups were fed the same amount of the same food. The difference of sodium excretion between the 2 groups was statistically significant for the first 3 days after starting the sodium deficient diet. After sodium was restored to the diet, urinary sodium increased to its prior level in both groups with no difference apparent in the return to the control levels. No significant difference was observed in the rate of excretion of potassium and 
Table III. Effects of Sodium Restriction on Urinary Excretion of Electrolytes in Hypertensive and Normotensive Rats

\begin{tabular}{|c|c|c|c|c|c|c|c|}
\hline Period & Day & \multicolumn{2}{|c|}{$\begin{array}{l}\text { Sodium (mEq./24 hours) } \\
\text { Hyperten- } \\
\text { sive }\end{array}$} & $\begin{array}{l}\text { Potassium (m } \\
\text { Hyperten- } \\
\text { sive }\end{array}$ & $\begin{array}{l}\mathrm{Eq} / 24 \text { hours }) \\
\text { Normoten- } \\
\text { sive }\end{array}$ & $\begin{array}{l}\text { Chloride (m } \\
\text { Hyperten- } \\
\text { sive }\end{array}$ & $\begin{array}{l}\text { Qq./24 hours) } \\
\text { Normoten- } \\
\text { sive }\end{array}$ \\
\hline \multirow{5}{*}{ 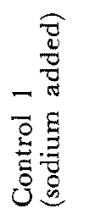 } & 1 & $1.70 \pm 0.20$ & $1.71 \pm 0.12$ & $1.74 \pm 0.13$ & $1.89 \pm 0.14$ & $3.26 \pm 0.20$ & $2.98 \pm 0.14$ \\
\hline & 2 & $1.76 \pm 0.13$ & $1.81 \pm 0.19$ & $1.92 \pm 0.09$ & $1.86 \pm 0.21$ & $3.18 \pm 0.14$ & $3.04 \pm 0.19$ \\
\hline & 3 & $1.73 \pm 0.14$ & $1.42 \pm 0.10$ & $2.23 \pm 0.12$ & $1.92 \pm 0.10$ & $3.44 \pm 0.19$ & $2.85 \pm 0.14$ \\
\hline & 4 & $1.74 \pm 0.05$ & $1.46 \pm 0.17$ & $2.12 \pm 0.11$ & $0.89 \pm 0.12$ & $3.46 \pm 0.11$ & $2.72 \pm 0.15$ \\
\hline & 5 & $1 \cdot 71 \pm 0.08$ & $1.75 \pm 0.11$ & $2.05 \pm 0.11$ & $2.09 \pm 0.29$ & $3.42 \pm 0.14$ & $3.50 \pm 0.16$ \\
\hline \multirow{5}{*}{ 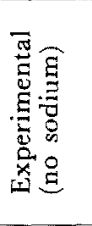 } & 6 & $0.135 \pm 0.018$ & $0.219 \pm 0.026 *$ & $2.08 \pm 0.11$ & $1.86 \pm 0.22$ & $1.68 \pm 0.09$ & 0.10 \\
\hline & 7 & $0.017 \pm 0.003$ & $0.038 \pm 0.008 *$ & $2.01 \pm 0.19$ & $2.19 \pm 0.26$ & $1.46 \pm 0.06$ & $1.33 \pm 0.16$ \\
\hline & 8 & $0.013 \pm 0.003$ & $0.023 \pm 0.003 *$ & $2.05 \pm 0.19$ & $2.09 \pm 0.15$ & $1.38 \pm 0.03$ & $1.4 I \pm 0.04$ \\
\hline & 9 & $0.011 \pm 0.009$ & $0.017 \pm 0.002$ & $1.91 \pm 0.19$ & $2.05 \pm 0.07$ & $1.37 \pm 0.12$ & $1.61 \pm 0.16$ \\
\hline & 10 & $0.007 \pm 0.002$ & $0.011 \pm 0.002$ & $1.98 \pm 0.28$ & $2.06 \pm 0.16$ & $1.42 \pm 0.12$ & $1.42 \pm 0.07$ \\
\hline \multirow{5}{*}{ 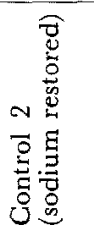 } & 11 & $0.81 \pm 0.18$ & $1.16 \pm 0.10$ & $2.29 \pm 0.09$ & $2.35 \pm 0.25$ & $2.86 \pm 0.17$ & $3.00 \pm 0.25$ \\
\hline & 12 & $1.96 \pm 0.14$ & $1.89 \pm 0.10$ & $2.00 \pm 0.19$ & $2.12 \pm 0.06$ & $3.58 \pm 0.22$ & $3.34 \pm 0.21$ \\
\hline & 13 & $1.87 \pm 0.08$ & $1.58 \pm 0.12$ & $2.29 \pm 0.21$ & $2.12 \pm 0.08$ & $3.76 \pm 0.15$ & $3.23 \pm 0.15$ \\
\hline & 14 & $1.80 \pm 0.09$ & $1.67 \pm 0.12$ & $2.33 \pm 0.16$ & $2.20 \pm 0.14$ & $3.74 \pm 0.22$ & $3.18 \pm 0.09$ \\
\hline & 15 & $1.83 \pm 0.11$ & $1.64 \pm 0.09$ & $2.28 \pm 0.13$ & $2.04 \pm 0.08$ & $3.81 \pm 0.16$ & $3.22 \pm 0.14$ \\
\hline
\end{tabular}

Values are means $\pm S E$.

* $P$ value of difference between hypertensive and normotensive: $0.05 \gg 0.02$

chloride in the urine between the 2 groups throughout this experiment.

\section{Discussion}

Differences in the response of body weight and urinary output of hypertensive and normotensive human subjects to the restriction of dietary sodium as shown by Perera and Blood ${ }^{11}$ were not observed in the rat. The observed reduction of urine output after sodium was withdrawn from the diet was also contrary to the results of Renwick et al. ${ }^{2)}$ who reported an increased urine volume after sodium restriction in both hypertensive and normotensive human subjects. Hypertensive rats in the present experiments showed polyuria associated with polydipsia and hyposthenuria as compared with normotensive animals which correlated well with the level of the systolic blood pressure. The observed polydipsia is obviously secondary to the polyuria and essential for maintaining homeostasis. ${ }^{6-7)}$

The observed decrease in urinary sodium excretion in hypertensive as compared to normotensive rats on a sodium free dict reflccts the tendency of hypertensive animals to retain sodium more efficiently than normotensives after 
sodium withdrawal, as is also the case apparently in the human who tolerates a low sodium diet for a longer time without any discomfort as compared with normotensive subjects. ${ }^{1)}$ Green et al. ${ }^{10)}$ noted that water and sodium excretion correlated with mean blood pressure in human subjects, whereas Hanenson et al. ${ }^{11 \prime}$ attributed the abnormality of water and sodium excretion in hypertensives to the increase of blood flow in the vasa recta secondary to hypertension.

An alternative explanation for the difference in response of hypertensive and normotensive subjects may be sought in the changes in renin and aldosterone secretion induced by sodium depletion. ${ }^{12)-16)}$ There is evidence to indicate that the secretion of aldosterone is stimulated in sodium depleted animals ${ }^{12}$, 17), 18) and Brown et al. ${ }^{19)}$ observed the usual increase in plasma renin in normotensive dogs without any significant change in blood pressure during sodium depletion.

On the other hand, it has been well known that patients with adrenal hypofunction excrete more sodium into urine than men with normal adrenal function after sodium depletion. ${ }^{20)}$ The difference of urinary sodium excretion observed in present experiments might suggest a difference in aldosterone stimulating effect of sodium depletion between hypertensive rats and normotensive ones.

\section{ACKNOWLedgements}

The technical assistance of Mrs. Patricia Dhahir is gratefully acknowledged.

\section{REFERENCES}

1. Perera, G. A. and Blood, D. W.: Am. J. Med. 1: 602, 1946.

2. Renwick, R., Robson, J. S., and Stewart, C. P.: J. Clin. Invest. 34: 1037, 1955.

3. Loomis, D. and Jett-Jackson, C. E.: Arch. Path. 33: 735, 1942.

4. Harvey, S. G.: Arch. Int. Med. 6: 12, 1910.

5. Friedman, M. and Freed, S. C.: Proc. Soc. Exp. Biol. Med. 70; 670, 1949.

6. Abrams, M., Defriez, A. I. C., Tosteson, D. C., and Landies, E. M.: Am. J. Physiol. 156: 233, 1949.

7. Mitchell, H. S. and Mendell, L. B.: Am. J. Physiol. 58: 211, 1921.

8. Oster, K. A. and Martinez, O.: J. Exp. Med. 78: 477, 1943.

9. Pearl, R. and Fairchild, T. E.: Am. J. Hug. 1: 253, 1921.

10. Green, D. M., Wedell, H. G., Wald, M. H., and Learned, B.: Circulation 6: 919, 1952.

11. Hanenson, I. B., Ricanati, E., and Polasky, N.: Circulation 28: 867, 1963.

12. Binnion, P. F., Davis, J. O., Brown, T. G., and Olichney, M. J.: Am. J. Physiol. 208: 655, 1965.

13. Brown, J. J., Davis, D. L., Lever, A. F, and Robertson, J. I. S.: Lancet ii: 278, 1963.

14. Brown, T. C., Davis, J. O., Binnion, P. F., and Olichney, M. J.: Physiologist 7: 96, 1964.

15. Laragh, J. H., Cannon, P. J, and Ames, R. P.: Canad. Med. Assoc. J. 90: 248, 1964. 
16. Veyrat, R., de Champlain, J., Boucher, R., and Genest, J.: Canad. Med. Assoc. J. 90: 215, 1964.

17. Davis, J. O,, Ayers, C. R., and Carpenter, C. C. J.: J. Clin. Invest. 40: 1466, 1961.

18. Winer, B. M.: J. Clin. Invest. 42: 994, 1963.

19. Biown, T. C., Davis, J. O., Olichney, M. J., and Johnston, C. I.: Circulat. Res. 18: 475, 1966.

20. Cutler, H. H., Power, M. H., and Wilder, R. M.: J.A.M.A. 111: 117, 1938. 